\title{
RINGS WHOSE UNITS COMMUTE WITH NILPOTENT ELEMENTS
}

\author{
GRIGORE CĂLUGĂREANU
}

\begin{abstract}
Rings with the property in the title are studied under the name of "uni" rings. These are compared with other known classes of rings and, since commutative rings and reduced rings trivially have this property, conditions which added to uni rings imply commutativity or reduceness are found.
\end{abstract}

MSC 2010. 13C99, 16D80, 16U80.

Key words. Uni ring, reduced ring, nilpotent-central ring, commuting nilpotents.

\section{REFERENCES}

[1] G. Călugăreanu, UU rings, Carpathian J. Math., 31 (2015), 157-163.

[2] G. Călugăreanu and T.Y. Lam, Fine rings: A new class of simple rings, J. Algebra Appl., 15 (2016), 1-18.

[3] G. Călugăreanu, A new class of semiprime rings, Houston J. Math., 44 (2018), 21-30.

[4] M. Chebotar, P.-H. Lee and E.R. Puczylowski, On prime rings with commuting nilpotent elements, Proc. Amer. Math. Soc., 137 (2009), 2899-2903.

[5] Y. Chun, Y.C. Jeon, S. Kang, K.N. Lee and Y. Lee, A concept unifying the Armendariz and NI conditions, Bull. Korean Math. Soc., 48 (2011), 115-127.

[6] P. Danchev and T.Y. Lam, Rings with unipotent units, Publ. Math. Debrecen, 88 (2016), 449-466.

[7] M.P. Drazin, Rings with central idempotent or nilpotent elements, Proc. Edinburgh Math. Soc., 9 (1958), 157-165.

[8] E. Jespers, G. Olteanu, A. del Rio and I. Van Gelder, Central units in integral group rings, Proc. Amer. Math. Soc., 142 (2014), 2193-2209.

[9] D. Khurana, G. Marks and A. Srivastava, On unit-central rings. In: Advances in Ring Theory, Birkhäuser, Springer Basel AG, Basel, 2010, 205-212.

[10] T.Y. Lam, Exercises in classical Ring Theory, Problem Books in Mathematics, SpringerVerlag, New York, 1995.

[11] L. Liang, L. Wang and Z. Liu, On a generalization of semicommutative rings, Taiwan. J. Math., 11 (2007), 1359-1368.

[12] W.K. Nicholson and H.J. Springer, Commutativity of rings with abelian or solvable units, Proc. Amer. Math. Soc., 56 (1976), 59-62.

[13] B. Ungor, S. Halicioglu, H. Kose and A. Harmanci, Rings in which every nilpotent is central, Algebras, Groups, Geometries, 30 (2013), 1-18.

Received February 1, 2018

Accepted June 8, 2018

DOI: $10.24193 /$ mathcluj.2018.2.03 
Babeş-Bolyai University Faculty of Mathematics and Computer Science

1 M. Kogălniceanu St. 400084 Cluj-Napoca

E-mail: calu@math.ubbcluj.ro 